\title{
Measuring the Effectiveness of AIOU Television for Students' Learning
}

\begin{abstract}
Syed Abdul Siraj ${ }^{*}$
Abstract

Television makes education different from other teaching modes such as book, lecture, radio, computer, etc. television can make better learning in circumstances where regular teacher and educational institutions are not available. The use of television for distance education is f high currency especially in poor countries, where resources are limited, and population is unmanageable. This study evaluates AIOU television programs for students learning. The study finds that AIOU TV airtime, day and duration are not suitable to students. Although students mostly rely on the textbook assignments and examination, nevertheless TV programs make up deficiency for the missed tutorials and benefit students to some extent in writing assignments.
\end{abstract}

Keywords: Television/AIOU/teaching tools

\section{Introduction}

Selecting appropriate teaching medium for learners is a key in distance education. Majority of the previous studies show that television has great benefits for learning in distance education which involves both audio and visual that has the ability to convert learning concepts and experiences easily into mental modes, such as imaginary or words, (Tony Bates, 1983). All distance education institutions in the world over are using television as one of the major tools for instruction. Allama Iqbal Open University (AIOU) is not using television very extensively. There are only a few numbers of courses that provide television component as a support medium for instruction. However, AIOU greatly relies on printed. The television programs used by AIOU have not properly been investigated for their effectiveness to know that how far they are helpful

\footnotetext{
* Professor, Department of Mass Communication, Allama Iqbal Open University, Islamabad
} 
for assignment and examination? Whether format, and presentation, are appropriate And do they contain elements for students' motivation

Evaluating educational television requires value judgment, assessment of students' achievement, continuation, termination or modification of an existing program or adoption of a new program. In this context, Chiam Tah Wen (1977) explains that there are two types of evaluation, the 'Summative', and the 'Formative' evaluation. Formative evaluation is conducted for the development of new educational television programs. In the formative evaluation, student learning needs, his readiness for learning and problems he encounters while learning are assessed. Its purpose is to assist the teacher and student to re-program the teaching aid. Summative evaluation is used to ascertain, or assess the effectiveness of the existing program in the context of teaching and learning. Its main purpose is to assist in certification or validation and in future selection. For effective production of educational TV programs, there is a need of collaboration between the researcher and producer and effort should be made to find out whether the system of analysis followed in the West is applicable to our situation. If not, what are the modifications that need to be done before any strategy is developed?

With the growth of research in distance education, Alistair (1984) argues that a number of writers have lamented at the apparent lack of a clearly defined paradigm for research and the few empirical findings relating to studying at a distance. In this regard Baath (1982) commented that "there is a severe lack of scientifically validated knowledge-someone would perform a very great service indeed if he/she would carry out a major empirical research study on the learning strategies of distance students-if possible including intensive studies by mean of interview and even observations of actual learner behavior."

The earlier research studies on educational television were focused on students' performance, reading habit, and comparing viewers with non-viewers. However these studies ignored the key element unfavorable attitudes towards the medium (Himmelweit, Oppenheim, 1958, Schramm, Lyle \& Parker, 1977, Furu, 1962, Campbell, 1962). Students’ responses to TV learning are influenced by several factors such as social class, intelligence, sex, personality, and learning style (Poole, 1998). It is generally observed that Television affacts attitude of the viewer deeply in an unobtrusive situation (Roshier, N. 1969). He explains in this regard that "our images of crime, for example, very much reflect its social reality rather than what we see of it via the media" and Nunnally J, C. (1961) views that "the same is true of our attitudes to mental illness." Kemelfield, (1972) finds that "children living in high-density immigrant 
areas in UK became far less certain of their pro-Pakistani feelings after viewing the program 'Our neighbor', which had the unintended effect of emphasizing differences rather than extolling uniqueness".

Bates, et al (1981) argues that analyzing usefulness of TV for learning through experimental research takes the students completely outside from the real learning context. Contrary to that, Parlett and Hamilton (1976) use the term "illuminative evaluation", which aims is to know what is really going on in learning process. In this method the focus is on the holistic studies investigated in a natural environment using qualitative and observational design. The need for evaluating educational television arises repeatedly in order to achieve maximum results from educational television. For that the media practitioners have to adapt themselves to new situation, keep abreast of innovations and harness the technology to the interest and needs of the students. Edward B. Lasher (1975) has presented a scale for evaluating educational television programs which he divided into three section: "The first section contains the bibliographic or identifying information such as the title, format of material, the producer, the distributor, length of the program, cost, and the year the program was produced. This section also contains information on content area, the specific audience, and objective of the program. The second section is about the description of the title, key concepts, and the skills used. The third section can be the evaluation itself" (Edward B. Lasher, 1975)

Major concern of research in education is how students learn through different ways. Alistair Morgam, (1984) is of the view that "learning is seen as the acquisition of pieces of knowledge and information. In contrast, learning can be seen as change in one's way of conceptualizing an idea, or aspect of reality." To him, "understanding, ideas, concepts or subject area, the learner must engage in a de-structuring of the knowledge or subject material, followed by a re-structuring of the material in relation to the learner's existing conceptual framework".

Findings from the studies of Margret, G. (1977) provides that students have different preferences for different program formats, for example, dramatic presentation, have mentally 'switched off' and missed the entire educational message of the program. Whereas some students get attracted by program like 'actuality' and they, too, miss the point of the program (Margret $G$, 1977). However specific production technique may cause intrusion on overall purpose of the program (Margret G, 1977).

A seminar in Poona (India) in 1975 on educational television concluded that "children programs should be devoted to experimenting 
traditional formats, including the use of realistic documentary, animation, puppetry, fantasy, etc. S.K. Mullick (1977) viewed that "no universal models could be applied in media decision because the response of audience, local culture condition and the availability of infrastructure have to be reckoned." He further emphasized that "television often descends to sheer entertainment. In communication the target audience has to be constantly borne in mind-its social, economic, and cultural profile-so that decision-making for media programs is relevant to the consumers. After all TV is a show business and its prime aim is to hold the interest of the audience, to make the audience believe that it is getting its money's worth. The switch-off knob is a nightmare for those who are in the entertainment trade. What we have to do is to face this great challenge of skillfully combining entertainment with content, if we want to bring in social change-which is the major objective of TV."

\section{AIOU Experience}

Pakistan started its TV broadcasting in the 60s with a small TV station at Lahore. Presently Pakistan Television (PTV) covers about 95\% of Pakistan's total area. PTV also runs educational programs in which a slate of two hour is given to Allama Iqbal Open University (AIOU). The transmission is run in the afternoon which is usually not suitable to AIOU students because mostly at that time they are engaged in the office work and house wives in the home chores. AIOU these days making all efforts for launching its own TV channel.

AIOU uses mostly Textbook, TV programs, Tutorials, and Radio programs for Metric, FA and BA levels students. For Masters' and higher level, the University also uses workshops, video conferences as tools for students learning. Textbook in Distance Education (DE) is taken as the main stay. Students receive textbook at the start of semester and use them for learning making assignment and preparing for examination. In some courses from Metric to BA levels, there are TV programs for supplementing students' learning. Tutorial is a teaching support takes place fortnightly for one and an half hour in the afternoon for which the University appoints relevant resource person called tutor. For remote students, the university arranges for correspondence tutorial. The University also provides radio component to its underrate students. 


\section{Research Question}

The investigation was determined through the following research questions.

What is the perception of the Allama Iqbal Open University students regarding the use of television as supplementary source of learning, and how far television as medium contributes to the students' learning?

The data was gathered through a structured questionnaire from the targeted students enrolled in spring 2004 Semester for BA courses, 'Economics', 'Islamiyat', 'Health and Nutrition', and 'Food and Nutrition'. These courses were selected as they had the support of TV programs. Enrolment of the selected course was 7000 students belonging to different parts of the Pakistan. The sample size (342) was proportionality and randomly selected from the university's admission list of spring 2004 being the sampling frame for this research.

\section{Results}

\section{AIOU Teaching Modes}

Figure 1 shows percentage distribution of students liking and disliking the textbook. As evident from the figure, $60 \%$ of the students liked textbook very much. However, 32\% just liked it, whereas $4 \%$ did not express their opinion (Chi-square $=226.947 ; p=.000$ ).

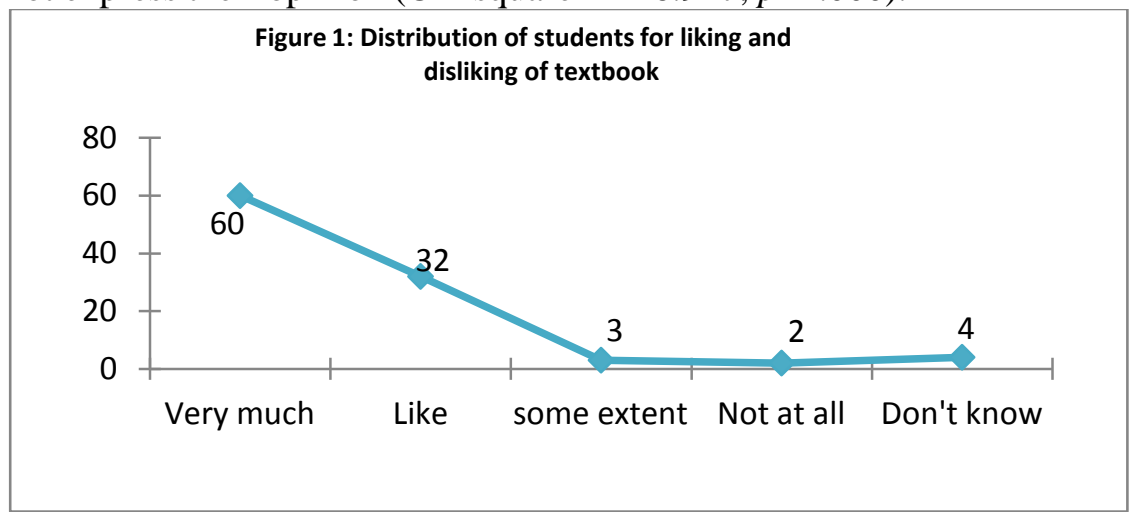

Figure 2 reports students' responses regarding likeness of TV programs as a supplementary teaching aid. As evident from the Figure, 33\% students liked TV programs, 25\% greatly liked, 23\% liked TV programs 
to some extent, $7 \%$ students did not like, and $13 \%$ students did not express their opinion on the liking and disliking of TV programs as a supplementary teaching aid (Chi-square $=34.361 ; p=.000$ ).

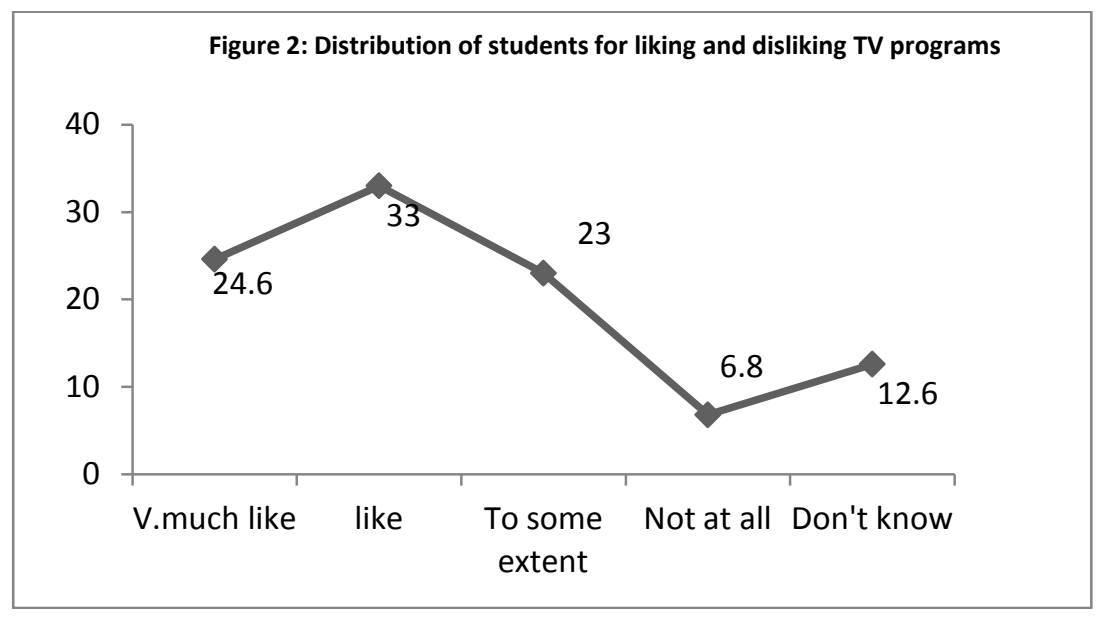

Figure 3 is about tutorial as teaching tool. As evident from the figure, students like $35 \%$ very like $19.4 \%$ somewhat like $23 \%$ and did not like $10 \%$ (Chi-square $=63.880 ; p=.000)$.

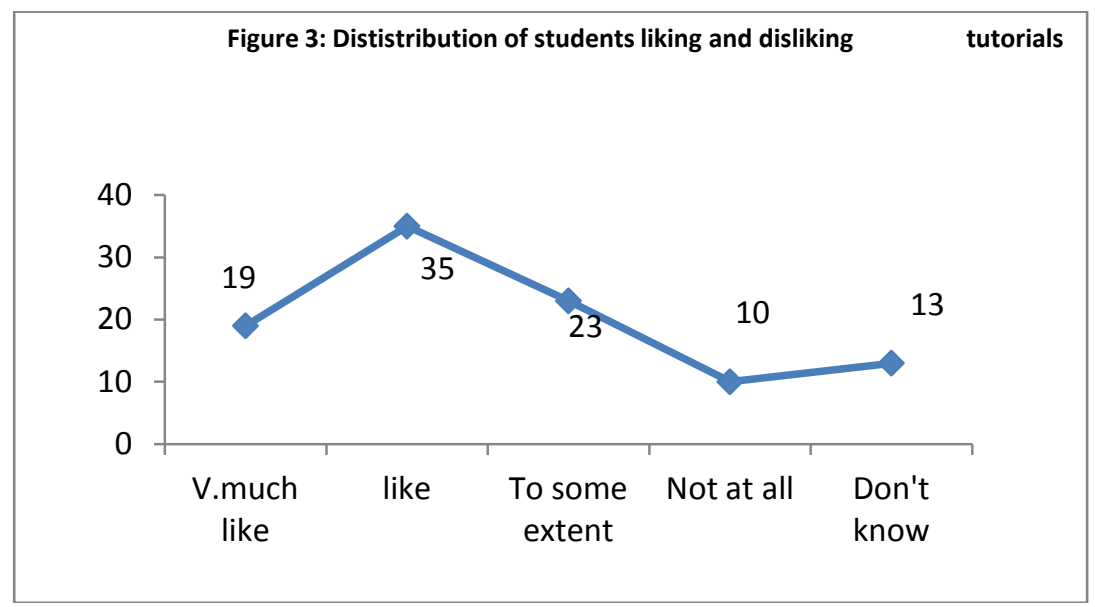

While comparing the usefulness of these teaching modes for study, majority students liked textbook mostly followed by TV, Radio and tutorial. 


\section{Students Exposure to AlOU TV}

Figure 4 indicates that majority of students did not watch AIOU TV frequently but watch them to some extent (Chi-square $=113.081$; $p=.000)$.

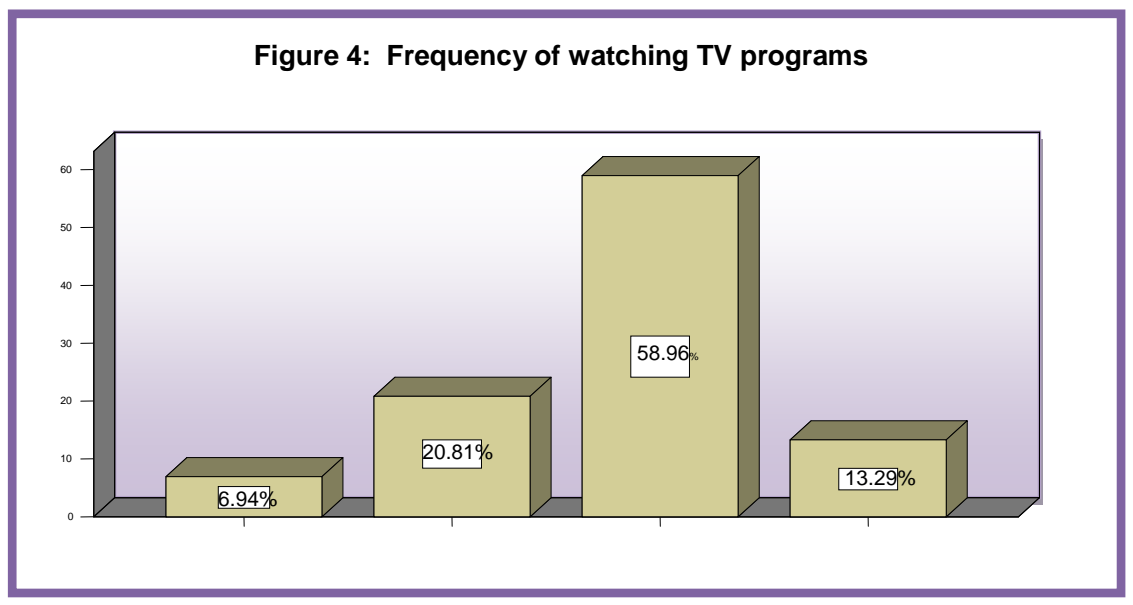

Figure 5 reveals the reason for not having watched AIOU TV programs by the students in their courses during the semester is the airtime which was not suit them (Chi-square $=152.024 ; p=.000)$.

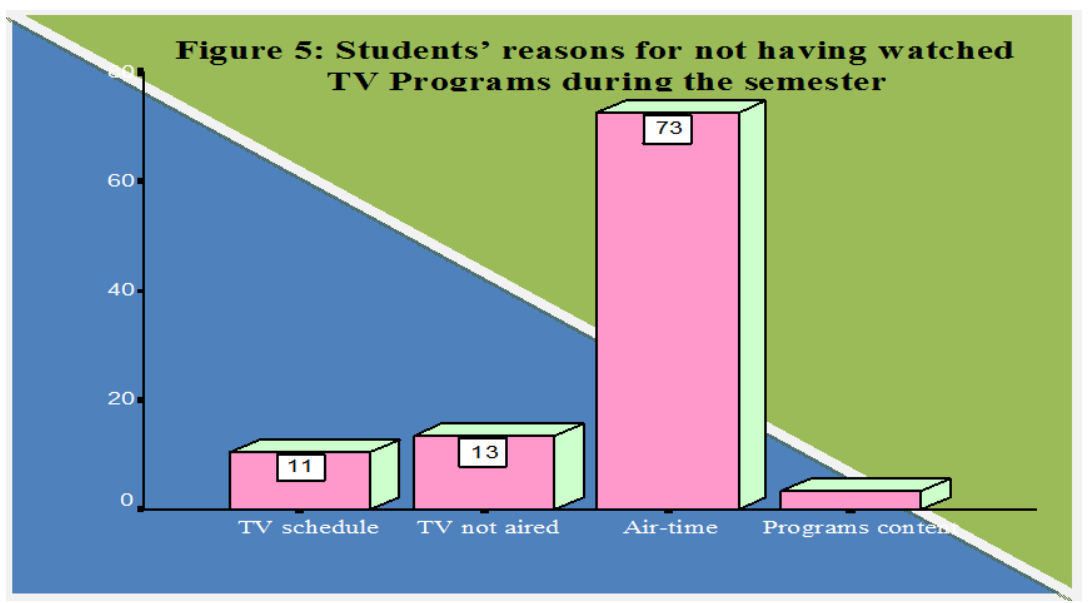

\section{Students' Need to Watch AIOU TV Programs During Semester}

Figure 6 tells that majority of students (40\%) were of the view that TV programs should be watched at the start of the semester. Whereas, $35 \%$ students viewed to have the TV program watched before writing the 
assignments. And $15 \%$ wanted to have TV programs of their courses watched just before the final exams. (Chi-square $=84.321 ; p=.000$ )

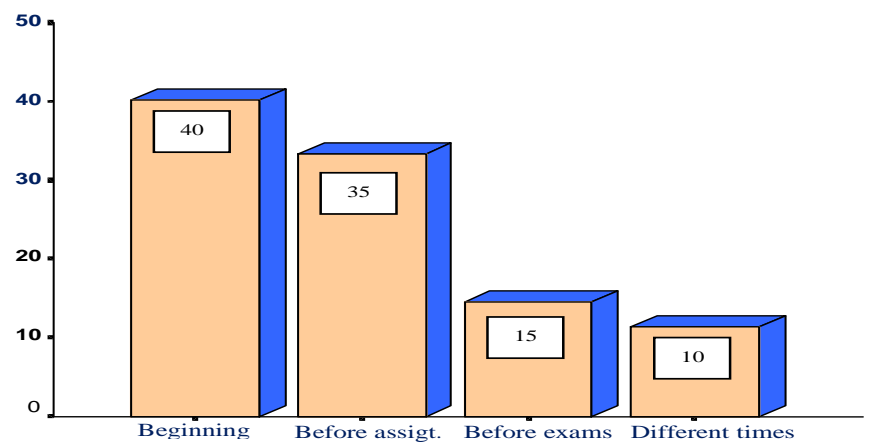

\section{Suitability of AIOU TV Broadcast Day and Time}

As evident from figure 8, great number of students (82\%) were interested to watch the AUIO TV program of their courses on Sunday (Chi-square $=34.783 ; p=.000$ ).

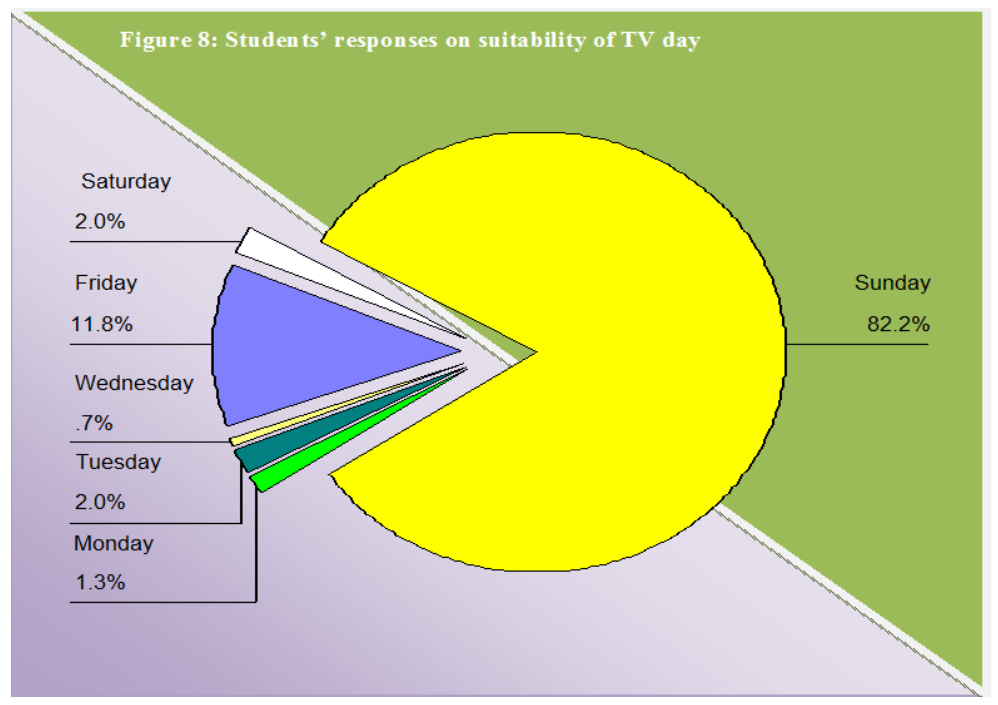

Writing Assignments Before and After Watching TV Programs

Data given in Figure 9 reveals students responses on writing assignments before and after watching TV programs. Majority of the students (51\%) responded that they have submitted their assignments 
after watching TV programs, whereas, 34\% students wrote their assignments before watching TV programs. There were also $15 \%$ who wrote assignments some time before and sometime after watching TV programs (Chi-square $=85.000 ; p=.000)$.

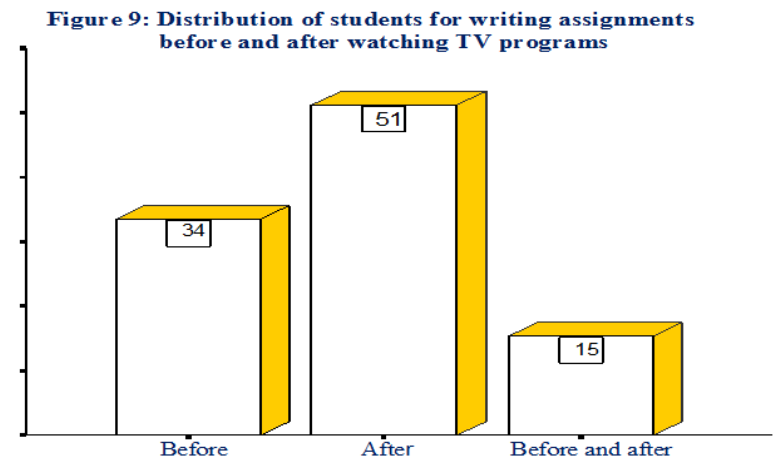

\section{Students' Discussion on TV Programs in tutorials}

Figure 10 gives percentage distribution of students' discussion on TV programs in tutorials during the semester. As clear from the Figure, $63 \%$ students discussed TV programs to some extent. Similarly, 28\% did not discuss TV program at all whereas, 18\% students reported that the often discussed TV programs in the tutorials (Chi-square $=22.950$; $p=.000)$.

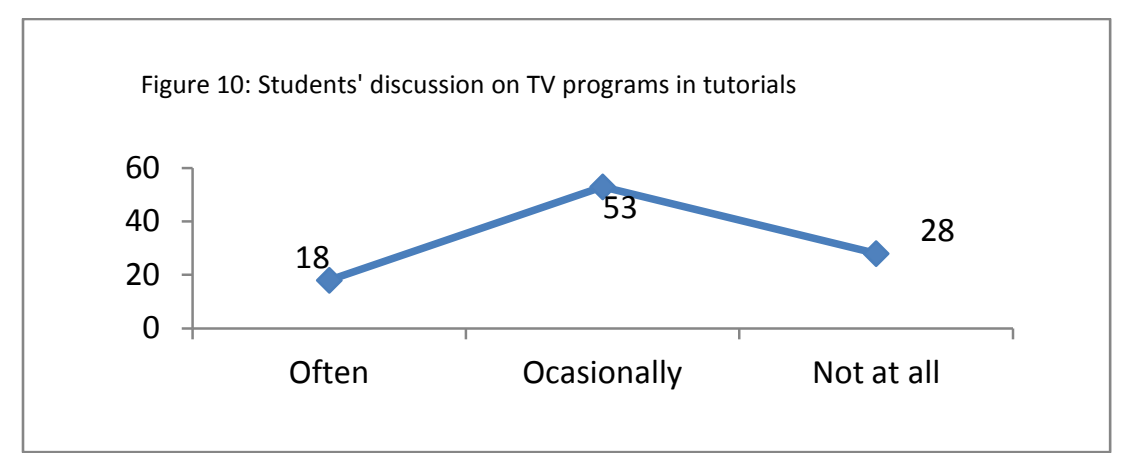

Discussion

In Pakistan, particularly in the AIOU, there is a major constraint with regard to the use of modern media techniques such as learning through internet, Skype, video links, etc. The practitioner's attitudes seem 
stranger and irrelevant when communicating with the student in general and rural students in particular. It is necessary to get familiar with the structure and methods of instruction through TV in order to develop an integrated approach of communication strategies. For effective production of educational TV programmes, there is a need of collaboration between the researcher and the producer and the aim should be to find out that the use of television is potentially useful for the students' studies. Evaluating the effectiveness of television for distance education is of high currency, particularly in the developing countries, where resources are limited, and population is unmanageable.

In the AIOU experience, textbook might be easy for comprehension as well as a great source of reliance. In the AIOU system, assignments and final examinations are based on textbooks. Television is the third choice of students for learning seems probably not coming to the expectations of students as a supplementary source of learning. Whereas students get sufficient benefit from tutorials as compare to TV.

Students' reasons for not watching AIOU TV program of their course is the unsuitability of their air time $(2.00 \mathrm{pm}$ to $3.00 \mathrm{pm})$. At this time, majority of the students are at their workplace. This is pertinent to mention that $54 \%$ of the total AIOU students are female and among them are house wives and female staying at home mostly engaged in home chores at this point in time. So majority students do not watch the TV program of their courses at this point in time. They wanted to have the TV program of their courses watched from $5.00 \mathrm{pm}$ to $7.00 \mathrm{pm}$ Students also wanted to have the TV program aired on Sunday being holiday Besides students responded that TV program be aired on Sunday.

AIOU Students are of the view to have TV programs at the beginning of semester. This might be due to the fact that students at the start of the semester wanted to make conceptual clarity for understanding the textbooks through TV programs and to write assignments confidently. Since the TV program does help student in writing the assignment if watched, so suitability of day and airtime will matter. The effectiveness of the TV program can also be evident from the fact that student while attending fortnightly tutorial discuss TV program relating to their courses. TV also makes up their deficiency for missed tutorials.

\section{Conclusion}

In the AIOU experience, textbook might be easy for comprehension as well as a great source of reliance and thus an effective medium in the system. TV airtime, day and duration are not suitable to students of 
AIOU as most of them are employed and thus rely on textbook for making assignments and preparing for examination. However students discuss TV program during the tutorial meetings and make up deficiency for the missed tutorials. AIOU TV is beneficial for students while writing assignments.

Notwithstanding, it has generally been observed that AIOU TV programs are made day in, day out, with no idea of how they will be effective for the students learning. For effective production of educational TV programmes, there is a need of collaboration between the researchers/academicians and the producers and the aim should be to find out the potential use of television for the students' effective leaning.

\section{References}

Alistair M. (1984) A report on qualitative methodologies in research in distance education. Australian Journal of Distance Education, 5, (8) pp. 252-265.

B Wade \& R. A. Poole (1983) Responses to educational Television. Journal of educational Television, Vol. 9, No. 1. pp. 22-30

Baat, J.A. (1982) Distance students' learning-Empirical findings and theoretical deliberations. Distance Education, 3, (1). pp. 6-27.

Christopher Jones, (1983) Piaget's Theories and some possible implications for Educational Television. Journal of Distance Educational Television, Vol. 9, No. 1, UK, Oxford shire. pp. 44-49

Compbell,W. J. (1962) Television and the Australian Adolescent. Sydney, Angus \& Robertson. pp. 176-80

Edward B. Lasher (1975) Evaluative Criteria of Non-Print material: A Compromise. Audio-visual Instruction, Evaluation \& Selection of Media, Volume 20, No. 4. pp. 17-18

Furu, T. (1962) Television and children's life. Tokyo, Japanese Broadcasting Cooperation. pp. 324-328 
G. F McVEY (1975) Components of an effective multi-media system for college and university instructor. Audio-visual Instruction. Evaluation \& Selection of Media, Value 20, No. 4. pp. 39-47

Hartman, P. \& Husband, C. (1974) Racism and the mass media, London, Davis Poynter. pp. 123-130

Himmelweit, Oppenheim \& Vine, 1958) Television and the children. oxford university Press. pp. 213

Howitt D. \& Cumberbatch, G. (1971) The ethnology of imitation unpublished article university of Leicester. pp. 136

Howitt D. (1973) Attitudes towards violence and mass media exposure, Gazette, 17. pp. 208-234.

Joan Bliss, (1983) Piaget's Theories and some possible implications for Educational Television. Journal of Distance Educational Television, Vol. 9, No. 1, UK, Oxfordshire. pp. 36

Kemelfield, G. (1972) The evaluation of school broadcasting: piloting a new approach. Leeds, university center for television research and London, ITA. pp. 154

M. Franceklein (1975). A perspective on improving the effectiveness of curriculum material. Audio-visual Instruction. Evaluation \& Selection of Media, Volume 20, No. 4. pp. 39.

Margret gallagaher, Programme Evaluation methods at the Open University. Evaluating Educational Television and Radio, Ed. Tony Bates and John Rabinson, Milton Keyens, 1977, page no.176.

Nunnally J. C, (1961) Popular Conceptions of Mental Health. New York, Holt, Rinehart \& Winston. pp. 342

Parlett. M. \& Hamilton, D. (1976) Evaluation is Illumination. In Tawny, D. (Ed) (1978) Curriculum Evaluation today: trends and Implication. London: Macmillan. pp. 79-85.

Roshier, N. (1969) Crime and the Press, Ph.D thesis. University of Newcastle Upon Tyne. pp. 195-197 
S. K. Mullick, Decision Making: A communication strategy in TV programmes building. Evaluating Educational Television and Radio, Ed. Tony Bates and John Rabinson, Milton Keyens, 1977, pp. 277-280.

Schramm, W., Lyle, J. \& Parker, E. (1977)In: Howe, M.J.A. (Ed) Television and Children. London, New University Education. pp. 67-73

Tony Bates, (1983) Piaget's Theories and some possible implications for Educational Television. Journal of Distance Educational Television, Vol. 9, No. 1, UK, Oxford shire, pp. 33

Tony Bates, A. W. (1981). Towards a better framework for evaluating the effectiveness of educational media. British Journal of Educational Technology, 12, (3), pp. 215-233

Tony Bates and Margaret Gallagher (1976) The Development of Research at the Open University. British Journal of Educational Technology, Vol. 1, No. 1, London. pp. 34-35. 
